\title{
Pharmacologic platelet anesthesia by glycoprotein Ilb/IIla complex antagonist and argatroban during in vitro extracorporeal circulation
}

\author{
Shinji Kanemitsu, MD \\ Masakatsu Nishikawa, MD \\ Koji Onoda, MDa \\ Takatsugu Shimono, MD \\ Hideto Shimpo, MD ${ }^{\mathrm{a}}$ \\ Akira Yazaki, MD \\ Kuniyoshi Tanaka, MD ${ }^{\mathrm{c}}$ \\ Hiroshi Shiku, MD ${ }^{\mathrm{b}}$ \\ Isao Yada, MD ${ }^{\mathrm{a}}$
}

\footnotetext{
From the Department of Thoracic and Cardiovascular Surgery, ${ }^{a}$ and the 2nd Department of Internal Medicine, ${ }^{\mathrm{b}}$ Mie University School of Medicine, Mie, and the 2nd Department of Surgery, ${ }^{\mathrm{c}}$ Fukui Medical University, Fukui, Japan.

Supported in part by grants for research from the Ministry of Education, Science, Technology, Sports and Culture of Japan.

Received for publication May 8, 2002; revisions requested July 25, 2002; revisions received Aug 19, 2002; accepted for publication Aug 22, 2002.

Address for reprints: Masakatsu Nishikawa, $\mathrm{MD}, \mathrm{PhD}$, The 2nd Department of Internal Medicine, Mie University School of Medicine, 2-174 Edobashi, Tsu, Mie 514-8507, Japan (E-mail: nisikawa@clin.medic.mieu.ac.jp).

J Thorac Cardiovasc Surg 2003;126:428-35

Copyright $(92003$ by The American Association for Thoracic Surgery

$0022-5223 / 2003 \$ 30.00+0$

doi:10.1016/S0022-5223(02)73288-1
}

Objective: Contact between blood and the synthetic surfaces of a cardiopulmonary bypass circuit leads to platelet activation, and resultant platelet dysfunction contributes to postoperative bleeding. We compared the effects of various platelet inhibitors on preservation of platelet function during simulated cardiopulmonary bypass circulation.

Methods: Fresh human blood was recirculated in an in vitro cardiopulmonary bypass model circuit. We measured various platelet activation markers including expressions of PAC-1 and P-selectin, annexin V binding, and microparticle formations by means of whole-blood flow cytometry.

Results: Two types of glycoprotein IIb/IIIa complex antagonists, peptide-mimetic FK633 and abciximab and prostaglandin $\mathrm{E}_{1}$, significantly prevented platelet loss and the increase in binding of PAC-1, an antibody specific for fibrinogen receptor on activated platelets, during extracorporeal circulation of heparinized blood. These antagonists significantly suppressed but did not abolish P-selectin expression, annexin $\mathrm{V}$ binding, and microparticle formation. Anti-von Willebrand factor monoclonal antibody and aurin tricarboxylic acid (an inhibitor of glycoprotein Ib) had no effect on platelet activation during simulated cardiopulmonary bypass circulation. These data suggest that inhibition of fibrinogen binding glycoprotein IIb/IIIa complex is partly effective in attenuating platelet activation in a heparinized cardiopulmonary bypass model circuit. The direct thrombin inhibitor argatroban prevented platelet loss and expression of P-selectin significantly more than did heparin. A combination of FK633 with argatroban as a substitute for heparin further prevented platelet loss and platelet secretion during simulated cardiopulmonary bypass circulation, although the inhibition of microparticle formation was less.

Conclusion: The inhibition of both platelet adhesion and thrombin may be effective to preserve platelet number and function during cardiopulmonary bypass circulation.

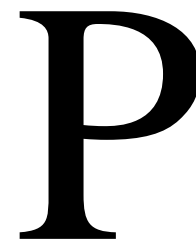

latelet consumption and dysfunction during cardiopulmonary bypass (CPB) result from contact activation with synthetic surfaces of CPB circuits and the shear stress of the flowing blood. ${ }^{1-3}$ The bleeding tendency during and after cardiac operations with CPB is largely caused by platelet dysfunction. ${ }^{4}$ Platelet dysfunction has been reproduced in vitro in recirculating heparinized human blood in a CPB model circuit composed of a tube and reservoir with a roller-head pump. ${ }^{1,5} \mathrm{We}$ have 
shown that the heparin-coated circuit maintains platelet aggregability in the in vitro extracorporeal circulation. ${ }^{5}$ Temporary pharmacologic inhibition of platelets (platelet anesthesia $^{6}$ ) during CPB is another potential strategy for preserving platelet number and function. We tested the effects on platelet consumption and functions during in vitro heparinized CPB circulation of various platelet inhibitors, including FK633 (a peptide-mimetic glycoprotein [Gp] IIb/ IIIa complex antagonist), ${ }^{7}$ abciximab (Fab fragment of antibody against GpIIb/IIIa complex), ${ }^{8,9}$ an anti-von Willebrand factor (vWF) monoclonal antibody (AJvW-2), ${ }^{10}$ aurin tricarboxylic acid (ATA, an inhibitor of platelet GpIb), ${ }^{11,12}$ and prostaglandin $\mathrm{E}_{1}\left(\mathrm{PGE}_{1}\right)$. To assess platelet activation during blood-synthetic surface contact, we quantitated platelet functional and structural alterations during a simulated CPB circulation with heparin used as an anticoagulant by means of whole-blood flow cytometry.

Platelets can be activated not only by contact activation with an in vitro CPB model circuit but also by coming in contact with thrombin, produced as a terminal event in coagulation cascades. ${ }^{5}$ Anticoagulation with heparin during CPB circulation does not entirely prevent surface-induced coagulation and the adherence of blood cells to membranes, even though heparin is the anticoagulant generally used in extracorporeal circulations (hemodialysis and CPB). The use of heparin can lead to other complications, including platelet dysfunction, thrombocytopenia, and lipid abnormalities, all predisposing toward cardiovascular disorders. ${ }^{13}$ Argatroban, a small-molecule synthetic direct thrombin inhibitor, binds rapidly and reversibly to both clot-bound and soluble thrombin. ${ }^{14}$ Because the utility of combining a direct thrombin inhibitor and a GpIIb/IIIa complex inhibitor has not been fully explored, we wanted to determine the efficacy of combining argatroban and FK633 to enhance inhibition of platelet activation during simulated extracorporeal circulation.

\section{Material and Methods \\ Reagents}

FK633, N-[4-(4-amidinophenoxy)butyryl]-a-L-aspartyl-L-valine, was provided by Fujisawa Pharmaceutical (Fujisawa Pharmaceutical Co, Ltd, Osaka, Japan), abciximab (Reopro) was purchased from Eli Lilly (Eli Lilly and Company, Indianapolis, Ind), and $\mathrm{PGE}_{1}$ was provided by Ono Pharmaceutical (Ono Pharmaceutical Co, Osaka, Japan). AJvW-2 was provided by Ajinomoto Pharmaceutical (Ajinomoto Pharmaceutical Co, Tokyo, Japan). ATA was purchased from Sigma (Sigma, St Louis, Mo), and low-molecular weight ATA polymers (molecular weight $<5 \mathrm{kd}$ ) were collected at $4{ }^{\circ} \mathrm{C}$ with a 5-kd cutoff filter (Ultrafree-4; Millipore Corporation, Bedford, Mass). Argatroban was provided by Mitsubishi Pharma (Mitsubishi Pharma Co, Osaka, Japan).

\section{Preparation of the Model of CPB}

The model circuits (surface area $0.01 \mathrm{~m}^{2}$ ) were assembled from standard medical-grade polyvinylchloride tubing (diameter 3.0 $\mathrm{mm}$ ) with polycarbonate connectors and reservoirs. ${ }^{5}$ These model circuits did not connect with oxygenators or air filters. Blood was drawn by venipuncture without stasis from informed volunteer staff members with a 17-gauge needle or taken into an ethylenediaminetetraacetic acid-treated tube for full blood count. Blood samples were diluted to approximate bypass hematocrit (25\%) with priming solution (Veen D; Nikkenkagaku, Tokyo, Japan). Heparin chloride was injected in a standard heparin dose used in clinical CPB (3 U/mL). In each experimental study $(\mathrm{n}=5)$, FK633 (100 and $500 \mathrm{nmol} / \mathrm{L}$ ), abciximab (2 and $10 \mu \mathrm{g} / \mathrm{mL})$, ATA (200 mg/ $\mu \mathrm{L})$, or $\mathrm{AJvW}-2(3.0 \mu \mathrm{g} / \mathrm{mL})$ was added to the reservoir just before circulation. In some experiments with 500-nmol/L FK633 $(\mathrm{n}=5)$, argatroban $(3 \mu \mathrm{g} / \mathrm{mL})$ was added to the circuit reservoir as a substitute for heparin. The blood priming solution was recirculated by a precisely shimmed, barely occlusive calibrated roller pump (Senko Medical Co, Ltd, Osaka, Japan) for 3 hours at a rate of equal to twice the circulating volume per minute $(100 \mathrm{~mL} / \mathrm{min})$. Blood temperature was maintained at approximately $28^{\circ} \mathrm{C}$. Shear stress $(\gamma)$ was calculated as follows: $\gamma=4 \eta \mathrm{Q} / \pi \mathrm{r}^{3}$, where $\eta$ is viscosity, $Q$ is blood flow, and $r$ is tube radius. Shear stress in the model circuit was approximately $30 \mathrm{dyne} / \mathrm{cm}^{2}$.

\section{Blood Sampling and Platelet Preparation}

Samples were taken at six times: (1) before circulation; (2) 5 minutes, (3) 60 minutes, (4) 120 minutes, and (5) 180 minutes after beginning circulation; and (6) 120 minutes after the completion of circulation. Whole blood samples were separated into two parts; one mixed with ethylenediaminetetraacetic acid was analyzed for platelet counting with Sysmex KX-21 (Sysmex Co, Kobe, Japan), whereas the other was immediately mixed with 1 volume of $3.8 \%$ sodium citrate solution to 9 volumes of whole blood for flow cytometry.

\section{Flow Cytometry of Activated Platelets and Platelet- Derived Microparticles}

We detected activated platelets in whole blood with a modification of the whole-blood flow cytometry method, ${ }^{15-17}$ as described in detail here. The following monoclonal antibodies were used for this study: SZ2 (Immnotech, Marseilles, France), which reacts with the vWF-binding site of the $\alpha$-chain of GpIb; SZ22 (Immnotech), which reacts with GpIIb; CLB-Thromb/6 (Immnotech), which reacts with P-selectin of $\alpha$-granule membrane; and PAC-1 (BD Biosciences, San Jose, Calif), which reacts with activated fibrinogen receptor GpIIb/IIIa complex. ${ }^{15}$ Increased expression of $\mathrm{P}$-selectin is indicative of $\alpha$-granule secretion. Whole blood containing platelets (about $1.0 \times 10^{6}$ ) was incubated with $10 \mu \mathrm{L}$ fluorescein isothiocyanate-conjugated (FITC) antibody for 30 minutes at room temperature and in the dark. Samples were fixed in $1 \%$ paraformaldehyde $\left(\mathrm{pH} \mathrm{7.3)}\right.$ at $4^{\circ} \mathrm{C}$ and analyzed with an Ortho Cytron Absolute flow cytometer (Ortho Diagnostic Systems, Tokyo, Japan). For each sample a gate was drawn around the platelet population, and the fluorescence signal from 10,000 individual cells was measured with the gain setting in logarithmic mode. When measuring GpIlb and GpIb, which were strongly expressed on all platelets at all times, the data were expressed as mean fluorescence intensity. The "flip-flop" of the platelet membrane, leading to the exposure of negatively charged phospholipids (predominantly phosphatidylserine) in platelet activation, was 


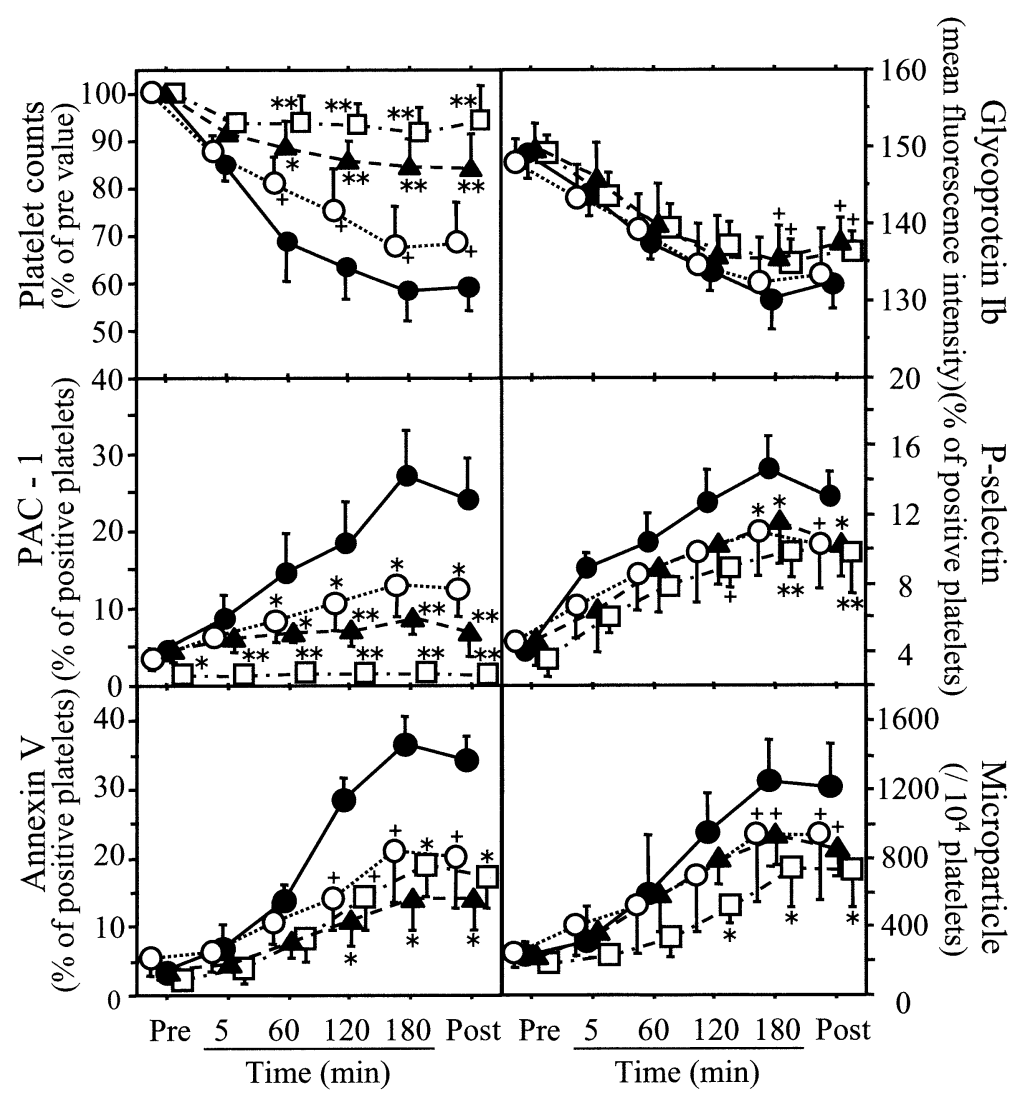

Figure 1. Effects of FK633, abciximab, and PGE , $_{1}$ on platelet counts; expressions of platelet surface Gplb, PAC-1, P-selectin, and annexin V; and PMP formation during simulated CPB circulation. Heparinized (3 U/mL) blood was recirculated with vehicle (control, filled circles) or with 500-nmol/L FK633 (filled triangles), 2- $\mu \mathrm{g} / \mathrm{mL}$ abciximab (open squares), or 50-ng/mL PGE ${ }_{1}$ (open circles). Data points represent mean; error bars represent SD (n $=5$ ). Plus signs indicate $P<.05$, asterisks indicate $P<.01$, and double asterisks indicate $P<.001$.

studied with FITC annexin V. ${ }^{18,19}$ Annexin V binding is indicative of phosphatidylserine exposure, which results in platelets with an increased procoagulant tendency. Platelets were incubated with FITC annexin V (BD PharMingen, San Diego, Calif) for 15 minutes at room temperature in the dark with calcium-containing annexin $\mathrm{V}$-binding buffer (10-mmol/L N-2-hydroxyethylpiperazine-N-2-ethanesulfonic acid and sodium hydroxide, $\mathrm{pH7.4,} \mathrm{140-}$ $\mathrm{mmol} / \mathrm{L}$ sodium chloride, $2.5-\mathrm{mmol} / \mathrm{L}$ calcium chloride) and analyzed with an Ortho Cytron Absolute. When measuring P-selectin, PAC-1, and annexin $\mathrm{V}$, which were present at low levels on unstimulated platelets and appear at significant levels on activation, the data were expressed as the percentage of fluorescencepositive platelets.

Platelet-derived microparticles (PMPs) were detected with a modification of a documented method. ${ }^{20}$ Whole blood was incubated with $10 \mu \mathrm{L} \mathrm{SZ22} \mathrm{(platelet} \mathrm{identifier} \mathrm{monoclonal} \mathrm{antibody)}$ for 30 minutes at room temperature in the dark. Only particles positive for GpIIb were gated, to distinguish PMPs from electronic noise. A sample of 10,000 FITC-positive particles in the PMP gate was then counted to determine the number of PMPs released per 10,000 platelets.

\section{Statistical Analysis}

StatView 5.0 (SAS Institute, Inc, Cary, NC) was used for statistical analysis. All data are given as mean \pm SD. Differences at each sampling of data between the two groups were assessed with the Student $t$ test. Comparisons between groups were made with 2 -factor repeated measures analysis of variance. When the analysis of variance indicated a significant effect, the differences between the two groups were evaluated with the Student $t$ test. The Pearson correlation coefficient was determined for the analysis of the relationship between platelet number and each platelet activation marker.

\section{Results}

Prevention of Platelet Function During in Vitro Extracorporeal Circulation by Various Platelet Inhibitors

When heparinized blood was recirculated with vehicle only (control, $\mathrm{n}=5$ ), platelet counts (initial count $10.98 \pm 1.80$ $\times 10^{4}$ cells $\left./ \mu \mathrm{L}\right)$ gradually fell to $58.2 \% \pm 6.2 \%$ of the initial level at 180 minutes, as shown in Figure 1 and Table 
TABLE 1. Dose-dependent effects of FK633, abciximab, and $\mathrm{PGE}_{1}$ on platelet activation during in vitro extracorporeal circulation

\begin{tabular}{|c|c|c|c|c|c|c|c|}
\hline & \multirow[b]{2}{*}{ Control } & \multicolumn{2}{|c|}{ FK633 } & \multicolumn{2}{|c|}{ Abciximab } & \multicolumn{2}{|c|}{$\mathrm{PGE}_{1}$} \\
\hline & & $100 \mathrm{nmol} / \mathrm{L}$ & $500 \mathrm{nmol} / \mathrm{L}$ & $2 \mu \mathrm{g} / \mathrm{mL}$ & $10 \mu \mathrm{g} / \mathrm{mL}$ & $50 \mathrm{ng} / \mathrm{mL}$ & $100 \mathrm{ng} / \mathrm{mL}$ \\
\hline \multicolumn{8}{|c|}{ Platelet counts $\left(10^{4}\right.$ cells $\left./ \mathrm{mm}^{3}\right)$} \\
\hline Before & $11.0 \pm 1.8$ & $10.3 \pm 0.9$ & $10.2 \pm 1.1$ & $10.3 \pm 2.0$ & $10.7 \pm 2.1$ & $11.7 \pm 1.3$ & $11.9 \pm 1.6$ \\
\hline $180 \mathrm{~min}$ & $6.3 \pm 1.0$ & $7.7 \pm 1.0^{*}$ & $8.6 \pm 0.8 \dagger$ & $9.5 \pm 1.9 \ddagger$ & $10.1 \pm 2.2 \ddagger$ & $7.9 \pm 0.6^{*}$ & $9.0 \pm 0.7 \ddagger$ \\
\hline \multicolumn{8}{|c|}{ Gplb (mean fluorescence intensity) } \\
\hline Before & $148.9 \pm 2.9$ & $149.9 \pm 3.6$ & $149.5 \pm 3.7$ & $148.8 \pm 2.6$ & $148.9 \pm 2.0$ & $148.0 \pm 2.9$ & $148.2 \pm 2.9$ \\
\hline $180 \min$ & $130.2 \pm 3.8$ & $130.4 \pm 3.2$ & $135.3 \pm 4.5^{*}$ & $134.7 \pm 3.1^{*}$ & $135.8 \pm 4.0^{*}$ & $132.3 \pm 5.9$ & $137.4 \pm 5.1^{*}$ \\
\hline \multicolumn{8}{|c|}{ Gpllb (mean fluorescence intensity) } \\
\hline Before & $168.0 \pm 4.2$ & $165.4 \pm 3.2$ & $168.3 \pm 2.9$ & $169.0 \pm 2.7$ & $169.6 \pm 0.8$ & $167.7 \pm 2.9$ & $167.3 \pm 2.9$ \\
\hline $180 \mathrm{~min}$ & $161.6 \pm 1.5$ & $161.8 \pm 4.6$ & $162.8 \pm 2.0$ & $164.1 \pm 2.0$ & $165.2 \pm 1.7$ & $160.0 \pm 5.0$ & $161.2 \pm 2.5$ \\
\hline \multicolumn{8}{|c|}{ PAC-1 (\% positive platelets) } \\
\hline Before & $4.6 \pm 1.2$ & $4.7 \pm 0.8$ & $4.5 \pm 1.5$ & $1.2 \pm 0.2$ & $1.2 \pm 0.4$ & $3.5 \pm 1.5$ & $3.3 \pm 1.4$ \\
\hline $180 \mathrm{~min}$ & $27.1 \pm 5.9$ & $26.4 \pm 7.5$ & $8.7 \pm 2.0 \ddagger$ & $1.5 \pm 0.7 \ddagger$ & $1.6 \pm 0.4 \ddagger$ & $13.1 \pm 4.0 \dagger$ & $6.8 \pm 2.8 \ddagger$ \\
\hline \multicolumn{8}{|c|}{ P-selectin (\% positive platelets) } \\
\hline Before & $4.0 \pm 0.7$ & $4.6 \pm 1.5$ & $4.7 \pm 1.5$ & $3.6 \pm 1.0$ & $3.5 \pm 1.3$ & $4.5 \pm 0.3$ & $4.3 \pm 0.3$ \\
\hline $180 \mathrm{~min}$ & $14.6 \pm 1.9$ & $11.4 \pm 2.8 \dagger$ & $11.7 \pm 2.5 \dagger$ & $9.9 \pm 1.6 \ddagger$ & $9.5 \pm 2.5 \ddagger$ & $11.3 \pm 2.6 \dagger$ & $8.1 \pm 1.4 \ddagger$ \\
\hline \multicolumn{8}{|c|}{ Annexin V (\% positive platelets) } \\
\hline Before & $3.5 \pm 0.8$ & $3.6 \pm 1.3$ & $3.6 \pm 1.0$ & $2.3 \pm 1.0$ & $2.3 \pm 1.0$ & $5.4 \pm 2.4$ & $5.1 \pm 1.7$ \\
\hline $180 \min$ & $36.6 \pm 4.1$ & $16.8 \pm 4.3 \dagger$ & $14.1 \pm 4.5 \dagger$ & $19.1 \pm 4.6 \dagger$ & $14.5 \pm 5.7 \dagger$ & $21.0 \pm 7.3^{*}$ & $9.4 \pm 1.9 \ddagger$ \\
\hline \multicolumn{8}{|c|}{ PMPs (per $10^{4}$ platelets) } \\
\hline Before & $227 \pm 81$ & $239 \pm 38$ & $221 \pm 38$ & $180 \pm 38$ & $199 \pm 45$ & $245 \pm 84$ & $233 \pm 56$ \\
\hline $180 \mathrm{~min}$ & $1241 \pm 250$ & $1136 \pm 358$ & $928 \pm 182^{*}$ & $737 \pm 227 \dagger$ & $466 \pm 217 \dagger$ & $940 \pm 393^{*}$ & $692 \pm 167 \dagger$ \\
\hline
\end{tabular}

Platelet counts; platelet surface expressions of Gplb, Gpllb, PAC-1, P-selectin, and annexin V, and PMP counts in the control group and groups with antiplatelet drugs FK633 (100 and $500 \mathrm{nmol} / \mathrm{L}$ ), abciximab (2 and $10 \mu \mathrm{g} / \mathrm{mL}$ ), and $\mathrm{PGE}_{1}(50$ and $100 \mathrm{ng} / \mathrm{mL}$ ) before in vitro extracorporeal circulation and 180 minutes afterward. All data are shown as mean $\pm S D(n=5)$.

${ }^{*} P<.05$ between the control group and the group given antiplatelet drugs.

$\dagger P<.01$ between the control group and the group given antiplatelet drugs.

$\ddagger P<.001$ between the control group and the group given antiplatelet drugs.

1. These results were similar to those reported previously for recirculated blood without platelet inhibitors. ${ }^{1,2}$ There was no significant change in the platelet surface expression of GpIIb throughout the circulation (Table 1). The percentage of PAC-1 (activated GpIIb/IIIa complex)-positive platelets increased from $4.6 \% \pm 1.2 \%$ before circulation to $8.6 \% \pm 3.1 \%$ after 5 minutes of extracorporeal circulation in the control circuits and reached the peak $(27.1 \% \pm 5.9 \%)$ after 180 minutes of circulation. The percentage of annexin V-positive platelets (surface expression of phosphatidylserine) increased from $3.5 \% \pm 0.8 \%$ at initial level to $36.6 \% \pm$ $4.1 \%$ after 180 minutes of circulation in the control group (Table 1). The expression of surface GpIb (mean fluorescence intensity) in the control group (148.9 \pm 2.9 at the initial level) decreased significantly during circulation, reaching the lowest level $(130.2 \pm 3.8)$ after 180 minutes of extracorporeal circulation, as reported previously elsewhere. ${ }^{6}$ The expression (percentage of positive platelets) of platelet surface P-selectin (the integral membrane protein of $\alpha$-granule) increased from $4.0 \% \pm 0.7 \%$ before circulation to $8.9 \% \pm 0.9 \%$ after 5 minutes of extracorporeal circulation and reached the peak $(14.6 \% \pm 1.9 \%)$ after 180 minutes of circulation. During extracorporeal circulation the release of PMPs was increased from $227 \pm 81$ per $10^{4}$ platelets before circulation to $1241 \pm 250$ per $10^{4}$ platelets after 180 minutes of circulation.

GpIIb/IIIa complex antagonists FK633 (500 nmol/L) and abciximab $(10 \mu \mathrm{g} / \mathrm{mL})$ significantly inhibited the decrease in platelet counts induced by in vitro CPB circulation (Figure 1). These inhibitors dose dependently prevented platelet loss during heparinized CPB circulation (Table 1). $\mathrm{PGE}_{1}$ at $50 \mathrm{ng} / \mathrm{mL}$ also had a protective effect on platelet number, but the protective effect of $\mathrm{PGE}_{1}$ was less. Abciximab, FK633, and $\mathrm{PGE}_{1}$ blocked increases in PAC-1-positive platelets, annexin $\mathrm{V}$ binding, expression of P-selectin, and PMP formation during simulated CPB circulation (Figure 1 and Table 1). Among these drugs, abciximab appeared to be the most effective. Although abciximab completely blocked platelet loss and the increase in PAC-1-positive platelets, the antibody only attenuated expression of other functional markers such as P-selectin, annexin V binding, and PMP formation. We then analyzed the relationship between platelet counts and functional markers of platelet activation. The correlation coefficients between platelet number and expressions of PAC-1, annexin V, GpIb, P-selectin, and PMP generation were $-0.622(P<.0001),-0.527(P<.0001)$, $0.476(P=.0002),-0.557(P<.0001)$ and $-0.477(P<$ $.0001)$, respectively. Figure 2 shows data on the negative 

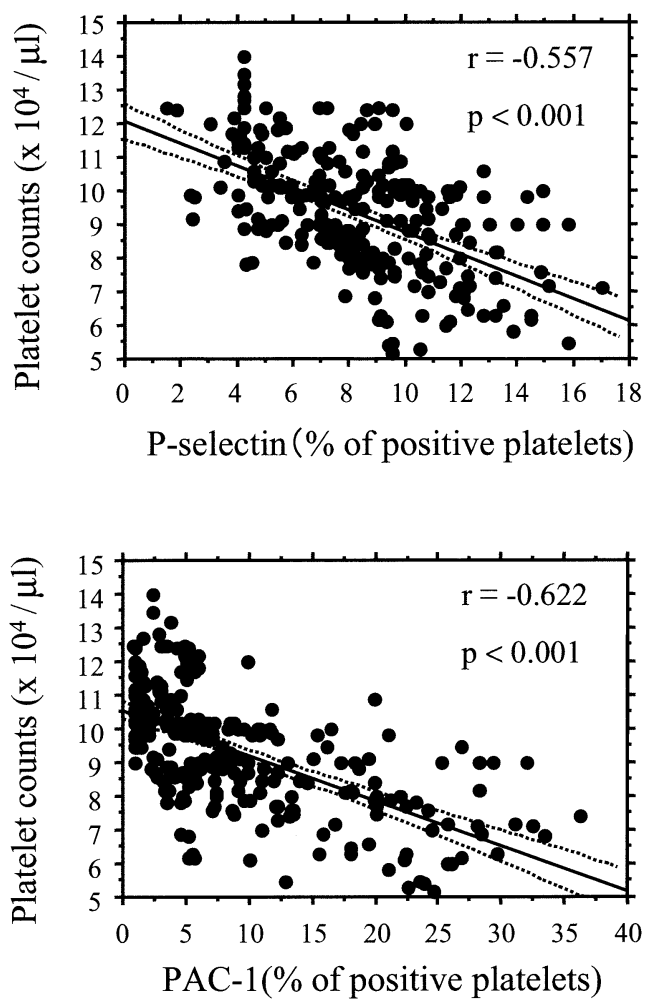

Figure 2. Correlation of platelet numbers and PAC-1 or P-selectin expressions during simulated $\mathrm{CPB}$ circulation.

correlation between platelet numbers and expressions of PAC-1 and P-selectin. PAC-1 expression was most strongly correlated with the decrease in platelet count during simulated CPB circulation.

An anti-human vWF monoclonal antibody, AJvW-2, and a polymeric anionic aromatic compound, ATA, both of which inhibit vWF binding to platelet GpIb, did not prevent the decrease in thrombocyte counts during simulated CPB circulation, as shown in Figure 3. These inhibitors did not inhibit increases in PAC-1 expression, annexin V binding, P-selectin expression, and PMP formation during in vitro extracorporeal circulation.

\section{Combined Effects of Argatroban and FK633 on} Platelet Activation During Extracorporeal Circulation Because thrombin is formed and circulates during heparinized extracorporeal circulation, ${ }^{5}$ platelets probably are activated even though aggregation and adhesion are inhibited. Argatroban, a small-molecule synthetic direct thrombin inhibitor, binds rapidly and reversibly to both clot-bound and soluble thrombin. ${ }^{14}$ The relatively short elimination half-life of argatroban (40-50 minutes) and its reversible binding allow rapid achievement of therapeutic effects on initiation of therapy and rapid restoration of normal hemostasis on cessation of therapy. We tested argatroban in an in vitro extracorporeal circulation as a substitute for heparin.
As shown in Figure 4, argatroban alone better maintained the platelet number, and there was a lesser degree of increase in the expression of P-selectin than seen with heparin alone. In the group treated with FK-633 and argatroban, platelet counts at 180 minutes were significantly higher than those in the group given FK-633 and heparin. In the group given FK-633 and argatroban, expressions of PAC-1 and P-selectin at 180 minutes of extracorporeal circulation were also significantly more inhibited than seen in the group given FK-633 and heparin. However, there were no significant differences in annexin V binding and PMP formation between these two groups.

\section{Discussion}

Our study indicates that the decrease in platelet number was most strongly correlated with increase in the expression of PAC-1 during extracorporeal circulation with heparin, although other platelet activation markers tested also had negative correlations with platelet number. Gradual platelet consumption is thought to be the result of platelet adhesion and activation to foreign surfaces in the extracorporeal circuits, ${ }^{2}$ partly mediated by interaction of platelet GpIIb/ IIIa complex receptors and fibrinogen bound to the surfaces of bypass tubing. ${ }^{21}$ It seems reasonable to assume that the direct inhibition of interaction between active GpIIb/IIIa complex receptor and fibrinogen effectively contributes to preservation of platelet counts in CPB circulation. GpIIb/ IIIa complex antagonists abciximab and FK633 prevented platelet loss almost completely during simulated CPB circulation, whereas these drugs only attenuated platelet activation, as indicated by the expression of P-selectin $(\alpha-$ granule secretion) and annexin $\mathrm{V}$ binding (procoagulant activity). Although $\mathrm{PGE}_{1}$ inhibited platelet activation and preserved platelet function, the concentration of $\mathrm{PGE}_{1}$ was higher than noted in clinical use. ${ }^{22}$ In addition, $\mathrm{PGE}_{1}$ is a potent vasodilator that is rapidly metabolized in the pulmonary circulation, and therefore its clinical use could be limited. ${ }^{23}$ ATA, with a molecular mass of less than $5 \mathrm{kd}$, inhibited vWF-mediated platelet aggregation. ${ }^{11}$ Borgdorff and colleagues ${ }^{24}$ reported that ATA inhibited pump-induced platelet aggregation and the loss of platelets in an extracorporeal circuit under shear stress, which was higher than in our experimental condition. AJvW-2 (an anti-vWF monoclonal antibody) inhibited vWF binding to platelet GpIb by ristocetin and blocked $\mathrm{vWF-GpIb}$ interaction under conditions of a high shear rate. ${ }^{10} \mathrm{ATA}$ and $\mathrm{AJvW}-2$, inhibitors of interaction between vWF and GpIb, had no protective effect against platelet loss under our flow conditions with low shear stress (approximately $30 \mathrm{dyne} / \mathrm{cm}^{2}$ ). Temporary and reversible pharmacologic inhibition of platelet activation may be needed during CPB to reduce postoperative bleeding in cardiac surgery. Abciximab more effectively preserved platelet counts and function than did FK633 during 


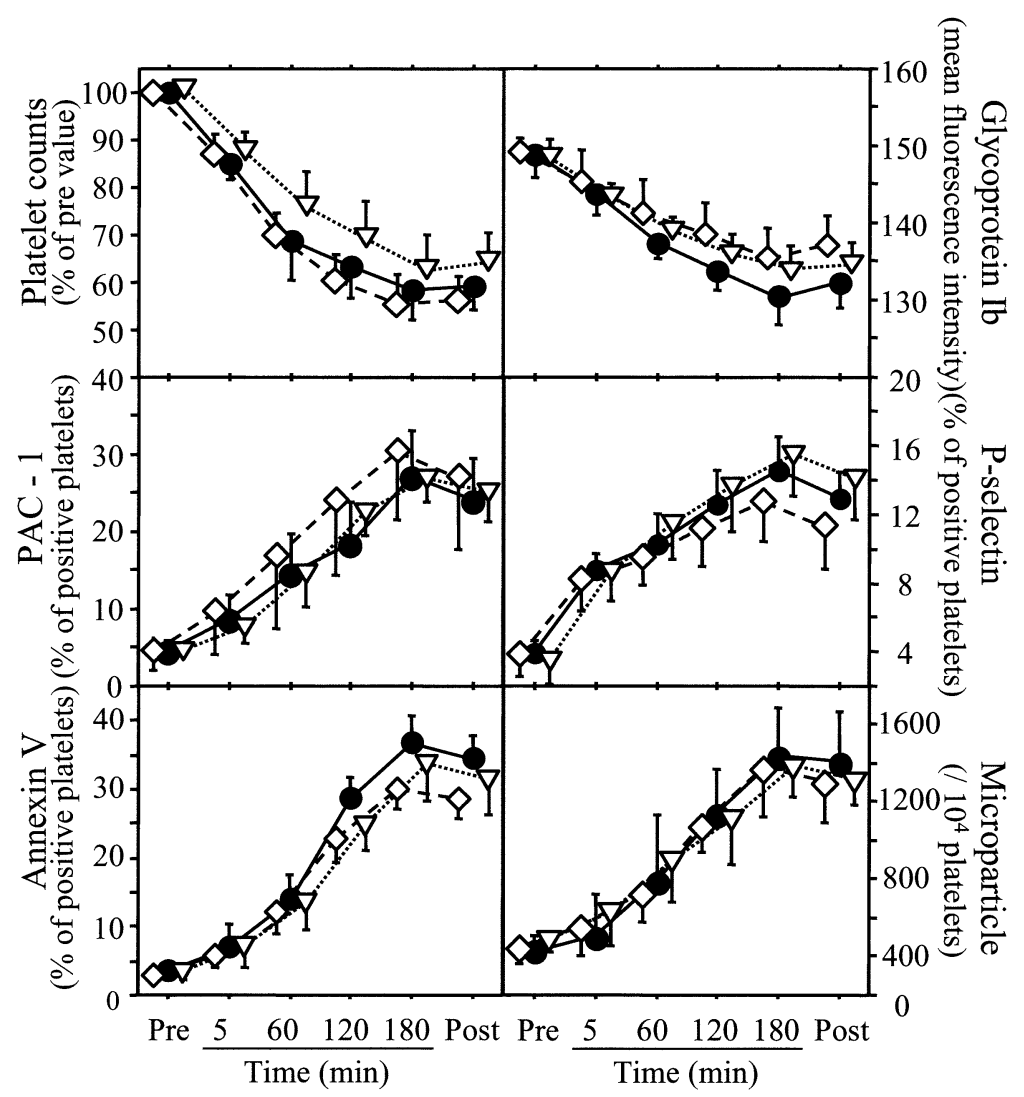

Figure 3. Effects of AJvW-2 and ATA on platelet counts; expressions of platelet surface Gplb, PAC-1, P-selectin, and annexin V; and PMP formation during simulated CPB circulation with heparin as anticoagulant. Heparinized $(3 \mathrm{U} / \mathrm{mL}$ ) blood was recirculated with vehicle (control, circles), $200 \mu \mathrm{g} / \mathrm{mL}$ ATA (diamonds), or $3.0 \mu \mathrm{g} / \mathrm{mL}$ AJvW-2 (inverted triangles). Data points represent mean; error bars represent SD (n=5).

extracorporeal circulation. Abciximab is a Fab fragment of chimeric mouse/human immunoglobulin $\mathrm{G}$ antibody. Its plasma half-life is 26 minutes, but the antiplatelet effect is prolonged and irreversible after administration. Elimination of abciximab from the human body in a clinical setting is considerably slower; the catabolic beta half-life was estimated to be 7 hours. ${ }^{8,9}$ Preoperative treatment with abciximab does not increase surgical mortality, but exposure before an operation has been reported to increase postoperative bleeding and transfusion requirements and is associated with a higher incidence of mediastinal reentry. ${ }^{25} \mathrm{Cur}-$ rently it is impossible to neutralize the action of abciximab at the end of extracorporeal circulation. Reversible GpIIb/ IIIa complex inhibitors tirofiban ${ }^{6}$ and eptifibatide ${ }^{26}$ have shown to reduce platelet activation during $\mathrm{CPB}$ and to decrease postoperative bleeding time in baboons. FK633 is an arginine-glycine-aspartic acid peptide-mimetic GpIIb/ IIIa complex antagonist with a reversible antiplatelet effect and its plasma half-life is 0.52 hours, ${ }^{7}$ which is shorter than those of tirofiban and eptifibatide. Therefore a low-molecular weight GpIIb/IIIa complex antagonist such as FK633 may be a potential candidate for platelet protection during CPB, although FK633, even at high doses, is less active against platelet loss and PAC-1 expression during an in vitro $\mathrm{CPB}$ circulation than is abciximab.

We have reported that the thrombin-antithrombin complex, a marker of thrombin generation, increases progressively and significantly during in vitro CPB circulation, even if heparinized platelets are recirculated, and then decreases after termination of pumping. ${ }^{5}$ In addition to contact activation of platelets, thrombin production may also contribute to activating platelets during simulated $\mathrm{CPB}$, the result being increases in $\mathrm{P}$-selectin expression, PAC-1 expression, and PMP formation. Heparin enhances platelet aggregation induced by agonists such as adenosine diphosphate and epinephrine ${ }^{27,28}$ and shear stress-induced platelet aggregation at both low and high shear stresses, ${ }^{29}$ whereas heparin inhibits platelet reaction resulting from the action of thrombin. ${ }^{30}$ Treatment with argatroban, a direct inhibitor of thrombin with a short half-life, prevented platelet loss and elevation of P-selectin more effectively than did heparin during a simulated $\mathrm{CPB}$ circulation. There appeared to be no 


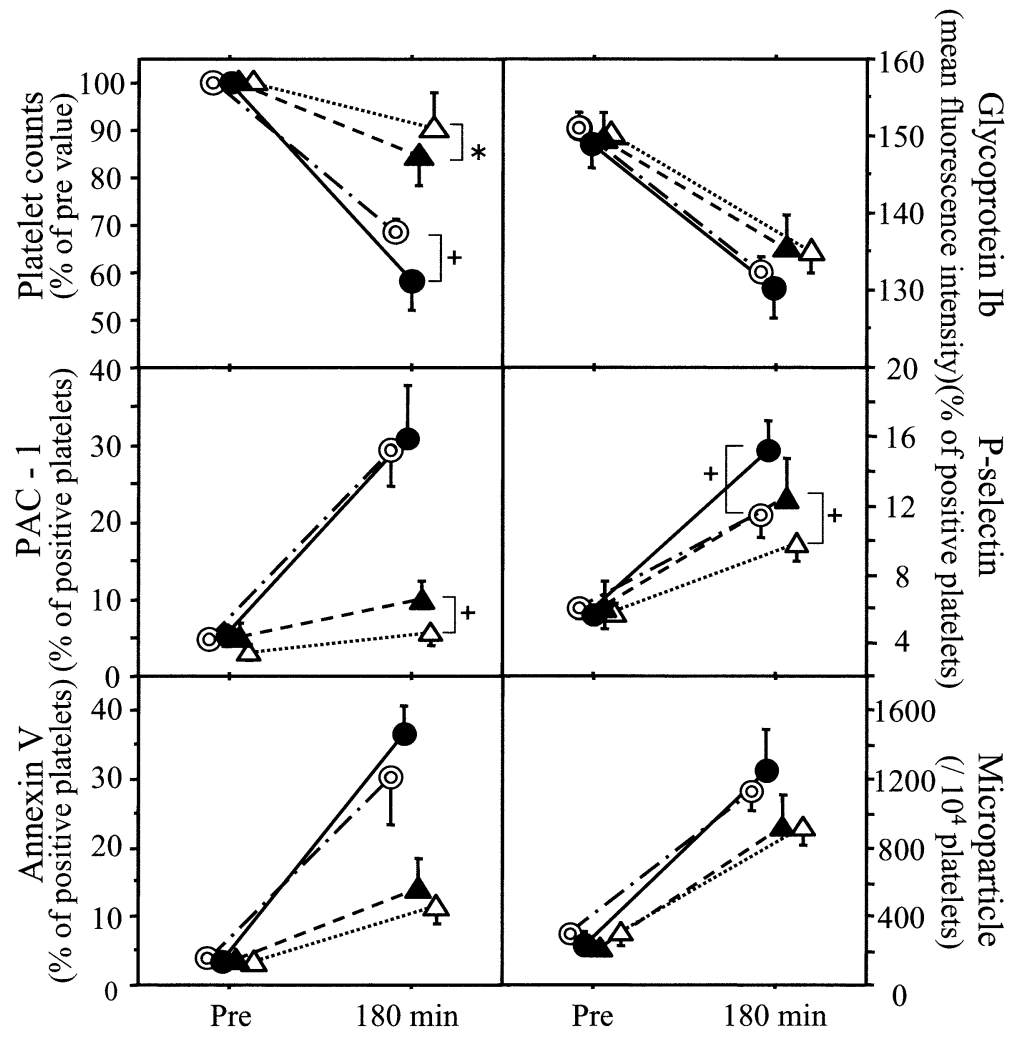

Figure 4. Combined effects of FK633 and argatroban on platelet counts; expressions of platelet surface Gplb, PAC-1, P-selectin, and annexin V; and PMP formation before circulation and at 180 minutes of in vitro extracorporeal circulation. Blood was recirculated with heparin $(3 \mathrm{U} / \mathrm{mL}$ ) alone (filled circles), heparin $(3 \mathrm{U} / \mathrm{mL})$ plus FK633 $(500$ $\mathrm{nmol} / \mathrm{L}$, open circles), argatroban $(3 \mu \mathrm{g} / \mathrm{mL}$ ) alone (filled triangles), or argatroban $(3 \mu \mathrm{g} / \mathrm{mL})$ plus FK633 (500 nmol/L, open triangles). Data points represent mean; error bars represent SD $(\mathrm{n}=5)$. Plus signs indicate $P<.05$ and asterisks indicate $P<.01$.

significant differences as to annexin $\mathrm{V}$ binding and PMP formation between these groups. The combination of argatroban and FK633 significantly inhibited platelet loss and expressions of PAC- 1 and P-selectin relative to findings with heparin and FK633. Despite full inhibition of PAC-1 expression, the combination of both inhibitors only partially prevented annexin V binding and PMP formation. Our findings suggest that inhibition of both thrombin and platelets is effective to preserve platelet number and function during CPB circulation. For cardiac operations, prompt and complete reversal of platelet inhibition is an absolute requirement. The clinical disadvantage of argatroban is that no neutralizing agent exists, such as protamine for heparin. Therefore these combined therapies still may not be sufficient to produce a meaningful decrease in postoperative bleeding after cardiovascular operation. Definitive assessments of efficacy and safety of combination of FK633 and argatroban await in vitro and in vivo studies. It has become increasingly evident that potent but reversible inhibition of both of platelet aggregation and thrombin activity will be needed if optimal extracorporeal circulation without platelet loss is to be achieved.

We are grateful to Dr S. Nomura for advice on measuring PMP formation by flow cytometry and to M. Ohara for critical comments on the manuscript.

\section{References}

1. Hennessy VL Jr, Hicks RE, Niewiarowski S, Edmunds LH Jr, Colman RW. Function of human platelets during extracorporeal circulation. Am J Physiol. 1977;232:H622-8.

2. Addonizio VP Jr, Macarak EJ, Niewiarowski S, Colman RW, Edmunds LH Jr. Preservation of human platelets with prostaglandin $\mathrm{E}_{1}$ during in vitro simulation of cardiopulmonary bypass. Circ Res. 1979; 44:350-7.

3. George JN, Pickett EB, Saucerman S, McEver RP, Kunicki TJ, Kieffer $\mathrm{N}$, et al. Platelet surface glycoproteins. Studies on resting and activated platelets and platelet membrane microparticles in normal subjects, and observations in patients during adult respiratory distress syndrome and cardiac surgery. J Clin Invest. 1986;78:340-8.

4. McKenna R, Bachmann F, Whittaker B, Gilson JR, Weinberg M. The hemostatic mechanism after open-heart surgery. II. Frequency of abnormal platelet functions during and after extracorporeal circulation. J Thorac Cardiovasc Surg. 1975;70:298-308. 
5. Hioki I, Nishikawa M, Onoda K, Shimono T, Shimpo H, Tanaka K, et al. A heparin-coated circuit maintains platelet aggregability in response to shear stress in an in vitro model of cardiopulmonary bypass. Thromb Haemost. 1998;80:437-42.

6. Hiramatsu Y, Gikakis N, Anderson HL, Gorman JH, Marcinkiewicz C, Gould RJ, et al. Tirofiban provides "platelet anesthesia" during cardiopulmonary bypass in baboons. J Thorac Cardiovasc Surg. 1997; 113:182-93.

7. Aoki T, Cox D, Senzaki K, Seki J, Tanaka A, Takasugi H, et al. The anti-platelet and anti-thrombotic effects of FK633, a peptide-mimetic GpIIb/IIIa antagonist. Thromb Res. 1996;81:439-50.

8. Coller BS. GpIIb/IIIa antagonists: pathophysiologic and therapeutic insights from studies of c7E3 Fab. Thromb Haemost. 1997;78:730-5.

9. Kleiman NS. Pharmacokinetics and pharmacodynamics of glycoprotein IIb-IIIa inhibitors. Am Heart J. 1999;138(4 Pt 2):S263-75.

10. Kageyama S, Yamamoto H, Nagano M, Arisaka H, Kayahara T, Yoshimoto R. Anti-thrombotic effects and bleeding risk of AJvW-2, a monoclonal antibody against human von Willebrand factor. $\mathrm{Br} \mathrm{J}$ Pharmacol. 1997;122:165-71.

11. Weinstein M, Vosburgh E, Philips M, Turner N, Chute-Rose L, Moake J. Isolation from commercial aurintricarboxylic acid of the most effective polymeric inhibitors of von Willebrand factor interaction with platelet glycoprotein Ib. Comparison with other polyanionic and polyaromatic polymers. Blood. 1991;78:2291-8.

12. Guo Z, Weinstein MJ, Phillips MD, Kroll MH. M(r) 6,400 aurin tricarboxylic acid directly activates platelets. Thromb Res. 1993;71: $77-88$.

13. Follis F, Schmidt CA. Cardiopulmonary bypass in patients with heparin- induced thrombocytopenia and thrombosis. Ann Thorac Surg. 2000;70:2173-81.

14. Tamao Y, Yamamoto T, Kikumoto R, Hara H, Itoh J, Hirata T, et al. Effect of a selective thrombin inhibitor MCI-9038 on fibrinolysis in vitro and in vivo. Thromb Haemost. 1986;56:28-34.

15. Shattil SJ, Cunningham M, Hoxie JA. Detection of activated platelets in whole blood using activation-dependent monoclonal antibodies and flow cytometry. Blood. 1987;70:307-15.

16. Janes SL, Wilson DJ, Chronos N, Goodall AH. Evaluation of whole blood flow cytometric detection of platelet bound fibrinogen on normal subjects and patients with activated platelets. Thromb Haemost. 1993; 70:659-66.

17. Metcalfe P, Williamson LM, Reutelingsperger CP, Swann I, Ouwehand $\mathrm{WH}$, Goodall $\mathrm{AH}$. Activation during preparation of therapeutic platelets affects deterioration during storage: a comparative flow cytometric study of different production methods. Br J Haematol. 1997; 98:86-95.
18. Thomas S, Metcalfe P, Goodall AH, Gray E. Monoclonal antibodies against platelet membrane glycoproteins IIb/IIIa and Ib alpha inhibit platelet dependent thrombin generation by different mechanisms. Thromb Haemost. 2000;84:98-103.

19. Furman MI, Krueger LA, Frelinger AL, Barnard MR, Mascelli MA, Nakada MT, et al. GpIIb-IIIa antagonist-induced reduction in platelet surface factor $\mathrm{V} / \mathrm{Va}$ binding and phosphatidylserine expression in whole blood. Thromb Haemost. 2000;84:492-8.

20. Nomura S, Shouzu A, Omoto S, Hayakawa T, Kagawa H, Nishikawa $\mathrm{M}$, et al. Effect of cilostazol on soluble adhesion molecules and platelet-derived microparticles in patients with diabetes. Thromb Haemost. 1998;80:388-92.

21. Gluszko P, Rucinski B, Musial J, Wenger RK, Schmaier AH, Colman $\mathrm{RW}$, et al. Fibrinogen receptors in platelet adhesion to surfaces of extracorporeal circuit. Am J Physiol. 1987;252(3 Pt 2):H615-21.

22. Cawello W, Schweer H, Muller R, Bonn R, Seyberth HW. Metabolism and pharmacokinetics of prostaglandin $\mathrm{E}_{1}$ administered by intravenous infusion in human subjects. Eur J Clin Pharmacol. 1994;46:275-7.

23. Kappa JR, Fisher CA, Todd B, Stenach N, Bell P, Campbell F, et al. Intraoperative management of patients with heparin-induced thrombocytopenia. Ann Thorac Surg. 1990;49:714-23.

24. Borgdorff P, van den Berg RH, Vis MA, van den Bos GC, Tangelder GJ. Pump-induced platelet aggregation in albumin-coated extracorporeal systems. J Thorac Cardiovasc Surg. 1999;118:946-52.

25. Lewis W, Collard CD. Does perioperative antithrombotic therapy increase the likelihood of a postoperative coagulopathy after cardiac surgery? Anesthesiology. 2000;92:1499-501.

26. Suzuki Y, Hillyer P, Miyamoto S, Niewiarowski S, Sun L, Rao AK, et al. Integrilin prevents prolonged bleeding times after cardiopulmonary bypass. Ann Thorac Surg. 1998;66:373-81.

27. Salzman EW, Rosenberg RD, Smith MH, Lindon JN, Favreau L. Effect of heparin and heparin fractions on platelet aggregation. J Clin Invest. 1980;65:64-73.

28. Westwick J, Scully MF, Poll C, Kakkar VV. Comparison of the effects of low molecular weight heparin and unfractionated heparin on activation of human platelets in vitro. Thromb Res. 1986;42:435-47.

29. Kawano K, Ikeda Y, Handa M, Kamata T, Anbo H, Araki Y, et al. Enhancing effect by heparin on shear-induced platelet aggregation. Semin Thromb Hemost. 1990;16:S60-5.

30. Sobel M, McNeill PM, Carlson PL, Kermode JC, Adelman B, Conroy R, et al. Heparin inhibition of von Willebrand factordependent platelet function in vitro and in vivo. J Clin Invest. 1991;87:1787-93. 